\title{
A unique model for SDH-deficient GIST: an endocrine-related cancer
}

\author{
James F Powers', Brent Cochran², James D Baleja², Hadley D Sikes³, Xue Zhang², Inna Lomakin', Troy Langford³, \\ Kassi Taylor Stein ${ }^{3}$ and Arthur S Tischler ${ }^{1}$
}

'Department of Pathology and Laboratory Medicine, Tufts Medical Center, Tufts University School of Medicine, Boston, Massachusetts, USA 2Department of Developmental, Molecular and Chemical Biology, Tufts University School of Medicine, Boston, Massachusetts, USA

3Department of Chemical Engineering, Massachusetts Institute of Technology, Cambridge, Massachusetts, USA

Correspondence should be addressed to J F Powers: jpowers1@tuftsmedicalcenter.org

\begin{abstract}
We describe a unique patient-derived xenograft (PDX) and cell culture model of succinate dehydrogenase-deficient gastrointestinal stromal tumor (SDH-deficient GIST), a rare mesenchymal tumor that can occur in association with paragangliomas in hereditary and non-hereditary syndromes. This model is potentially important for what it might reveal specifically pertinent to this rare tumor type and, more broadly, to other types of SDH-deficient tumors. The primary tumor and xenografts show a very high proliferative fraction, and distinctive morphology characterized by tiny cells with marked autophagic activity. It is likely that these characteristics resulted from the combination of the germline SDHB mutation and a somatic KRAS G12D mutation. The most broadly relevant findings to date concern oxygen and oxidative stress. In paragangliomas harboring $S D H x$ mutations, both hypoxic signaling and oxidative stress are putative drivers of tumor growth. However, there are no models for SDH-deficient paragangliomas. This related model is the first from a $S D H B$-mutated human tumor that can be experimentally manipulated to study mechanisms of oxygen effects and novel treatment strategies. Our data suggest that tumor growth and survival require a balance between protective effects of hypoxic signaling vs deleterious effects of oxidative stress. While reduced oxygen concentration promotes tumor cell survival, a further survival benefit is achieved with antioxidants. This suggests potential use of drugs that increase oxidative stress as novel therapies. In addition, autophagy, which has not been reported as a major finding in any type of SDH-deficient tumor, is a potential target of agents that might trigger autophagic cell death.
\end{abstract}

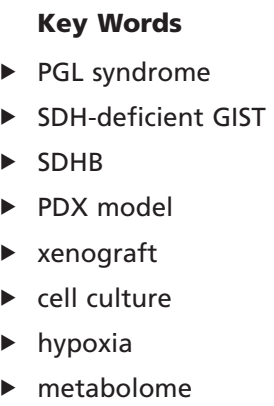

Endocrine-Related Cancer (2018) 25, 943-954

\section{Introduction}

SDH-deficient gastrointestinal stromal tumors (GISTs) are rare but sometimes lethal tumors that can occur in patients with paraganglioma (PGL) syndromes. These tumors do not harbor the KIT or PDGFRA mutations typical of conventional GISTs and are therefore not amenable to conventional GIST treatments with receptor tyrosine kinase inhibitors. They also metastasize to lymph nodes more frequently than conventional GISTs, and their clinical prognosis is not predictable by conventional risk stratification parameters (Boikos et al. 2016, Mullassery \& Weldon 2016, Ricci 2016). Similar to PGLs, there is currently no cure for SDH-deficient GIST other 
than complete surgical excision, and there is a paucity of experimental models.

This paper describes a unique PDX and cell culture model for basic and pre-clinical studies of SDH-deficient GIST. The model, which we have named 'the Ian GIST model', is derived from an aggressive gastric GIST that arose in a young man with a germline $S D H B$ mutation and family history of multiple paragangliomas. Despite a remarkable multi-institutional translational research effort aimed at developing an effective treatment ('the Ian GIST Project', https://www.forian.org/), the entire clinical course before the patient died was approximately 2 years. In addition to loss of SDHB protein expression and SDH activity, the tumor was found to harbor a somatic KRAS G12D mutation, possibly contributing to its aggressive behavior.

This GIST model is important for two reasons. First, it is a unique human-derived model for a rare type of tumor that occurs in patients with hereditary SDHB mutations. Although the basic metabolic defect in all SDH-deficient tumors is similar, different types of tumor such as GISTs and paragangliomas are likely to be affected by that defect in different ways because of intrinsic differences in their cells of origin. It is well established that different types of cancer as well as individually distinct cancers have varied genetic and epigenetic characteristics that dictate different approaches to treatment (Burgess et al. 2017) and that even therapeutic outliers can lead to new markers of drug sensitivity (Burgess et al. 2017). Second, because SDH-deficient GIST does have similarities to other SDHdeficient tumors, information gained from studying this model might also lead to increased understanding of other tumor types and to improved treatments for them.

\section{Materials and methods}

\section{Origin of the model}

The tumor of origin was a gastric GIST that arose in a 17-year-old patient who had a germline $S D H B$ mutation $(423+1 \mathrm{G}>\mathrm{A})$ and family history of paragangliomas in two male relatives, but was himself previously healthy. Approximately 3 months after resection of the primary tumor, he presented with a $15 \mathrm{~cm}$ recurrent tumor in the residual portion of stomach, with extensive local invasion and abdominal dissemination.

Our model was developed from a PDX established by a commercial service (Champions Oncology, Hackensack, NJ, USA) in nude mice from a tumor deposit in the patient's abdomen. With authorization from the deceased patient's family, we received cryopreserved passage 3 xenograft tissue and expanded through passage 6 in nude and/or NSG mice. This project is approved by the Institutional Review Board at Tufts Medical Center.

\section{Histology and immunohistochemistry}

Histologic sections of the primary tumor, the recurrence and xenografts were examined by a pathologist (AST) to assess phenotype drift in consecutive passages. Immunohistochemical stains were performed following previously reported protocols with antibodies shown in Supplementary Table 1 (see section on supplementary data given at the end of this article). All control tissues showed appropriate immunoreactivity.

\section{Electron microscopy}

Fragments of xenograft tissue were fixed in commercially prepared fixative (Electron Microscopy Sciences, Hatfield, PA, USA) containing 2.5\% glutaraldehyde and 2\% formaldehyde in $0.1 \mathrm{M}$ sodium cacodylate buffer. They were then postfixed in $2 \% \mathrm{OsO}_{4}$, dehydrated in a graded ethanol series followed by propylene oxide and embedded in Epon. Ultrathin $(90 \mathrm{~nm})$ sections on copper grids were stained with $0.2 \%$ lead citrate and $1 \%$ uranyl acetate and examined with a Philips 2085 electron microscope at $80 \mathrm{kV}$.

\section{Transcriptional profiling}

RNA sequencing was performed by the Tufts genomics core with an Illumina HiSeq 2000. Paired-end RNA sequencing data were preprocessed using Trimmomatic (Bolger et al. 2014) to cut or filter poor quality reads. The preprocessed data were then aligned using TopHat2 pipeline (Kim et al. 2013). The featureCounts software (Liao et al. 2014) was used to map reads to genes, and edgeR (Robinson et al. 2010) was used to calculate RPKM (Reads Per Kilobase of transcript per Million mapped reads) values for genes.

\section{Metabolomic analysis}

In vivo metabolomic analyses were performed to test whether the major metabolites produced in the GIST xenografts are consistent with metabolic profiles reported in SDH-deficient paragangliomas and in an SDH-deficient line of fibroblast-like cells derived from mouse adrenal glands (Letouze et al. 2013, Lussey-Lepoutre et al. 2015). ${ }^{1} \mathrm{H}$ NMR was used for unbiased metabolite profiling and 
${ }^{13} \mathrm{C}$-NMR was used to trace the metabolic fate of glucose and determine the contribution of glycolysis and/or TCA cycle/anaplerotic pathways to the metabolite profile (Bruntz et al. 2017). Four replicate subcutaneous tumor nodules (bilateral flank implants from two mice, each $1 \mathrm{~cm}$ in greatest dimension) were analyzed. A xenograft of a KIT-mutated, SDH-intact, GIST (GIST-TI) (Taguchi et al. 2002) in NSG mouse was used as an SDH-intact control. Thirty minutes before killing, the mice were injected intraperitoneally with a $3 \mathrm{mmol} / \mathrm{kg}$ dose of $100 \%$ uniformly ${ }^{13} \mathrm{C}_{6}$-labeled glucose (the natural abundance of ${ }^{13} \mathrm{C}$ is $1 \%$ ) (Eloqayli et al. 2004). Tumor tissue was dissected cold and frozen in liquid nitrogen. Metabolites were extracted with chloroform/methanol. To each frozen tissue sample, $0.4 \mathrm{~mL}$ of ice-cold methanol and $0.085 \mathrm{~mL}$ water were added and the tissue was minced to a fine grain on ice. After sonication to homogeneity, $0.4 \mathrm{~mL}$ of cold chloroform was added, which was then processed as described by Wu et al. (2008).

The polar methanol/water layer was dried using a speed-vac and reconstituted in $50 \mathrm{mM}$ phosphate $\mathrm{D}_{2} \mathrm{O}$ buffer $\mathrm{pH} 7.0$ with $0.5 \mathrm{mM}$ of NMR standard (DSS, 4,4-dimethyl-4-silapentane-1-sulfonic acid). ${ }^{1} \mathrm{H} \quad \mathrm{NMR}$ spectra of each sample were collected at $25^{\circ} \mathrm{C}$ on a Bruker Avance 600 spectrometer using 256 scans and a NOE1D pulse sequence. 13C NMR spectra were also measured using 10,000-20,000 scans. The $1 \mathrm{H}$ data were processed and analyzed using CHENOMX NMR Suite 8.0 to identify and quantify compounds present and measure their concentrations. Identity of compounds in 13C data were based on published reference spectra (Wishart et al. 2009) (and on $2 \mathrm{D}{ }^{1} \mathrm{H}-{ }^{13} \mathrm{C}$ correlation spectra using HSQC (heteronuclear single-quantum coherence).

\section{Immunoblots}

Protocols for routine protein extraction and immunoblotting were as previously described (Powers et al. 2000). Proteins were resolved on gradient $4-15 \%$ polyacrylamide gels to permit probing for a wide range of molecular weights. Blots were sequentially probed, stripped and re-probed with the same antibodies used for immunohistochemistry, at dilutions optimized for immunoblots.

For Redox immunoblots (Cox et al. 2010), frozen GIST tissue samples were first placed in petri dishes on ice and soaked with $100 \mu \mathrm{L}$ of $200 \mathrm{mM}$ methyl methane thiolsulfonate (MMTS, purchased from Sigma) in PBS $(1 \times)$. The samples were then sliced with razor blades and placed in a $1.5 \mathrm{~mL}$ tube along with an additional $900 \mu \mathrm{L}$ of
$200 \mathrm{mM}$ MMTS in PBS. The tissue samples were incubated on ice for $30 \mathrm{~min}$. After incubation, the tissue sample was centrifuged at $250 \boldsymbol{g}$ for $5 \mathrm{~min}$. The MMTS solution was removed from the tube and the cells were washed with $1 \mathrm{~mL}$ of PBS. The samples were then centrifuged and washed with PBS a second time. After centrifugation again, $100 \mu \mathrm{L}$ RIPA buffer with HALT protease inhibitor cocktail (1x, Thermo Fisher) was added to the samples. The samples were then homogenized with a manual tissue homogenizer. The lysed cells were then re-pelleted at $12,000 \boldsymbol{g}$ for $10 \mathrm{~min}$. The supernatant of the solution was then collected and the protein content in the solution was assessed via the BCA assay. Twenty micrograms of protein were loaded into a Tris-tricine acrylamide gel and subjected to SDS-PAGE under non-reducing conditions (i.e. with no $\beta$-mercaptoethanol in the sample buffer). After the separated lysates were transferred to a PVDF membrane (Bio-Rad) ( $1 \mathrm{~h}$ at $100 \mathrm{~V})$, the blot was blocked and incubated with either goat primary antibody for Prx2 (R\&D Systems, Catalog \# AF3489) (at a dilution of 1:800) or rabbit primary antibody for Prx3 (Abcam, Catalog \#ab129206) (at a dilution of $1: 10,000$ ) at $4^{\circ} \mathrm{C}$ overnight and then with donkey anti-goat IR 688 (Licor) (at a dilution of 1:10,000) or donkey anti-rabbit IR 800 (Licor) (at a dilution of $1: 10,000$ ) for $1 \mathrm{~h}$ at approximately $22^{\circ} \mathrm{C}$. $\beta$-Tubulin was used as a loading control for the blots. The tagged proteins were visualized using an Odyssey CLx Infrared Imaging System. In order to determine the fraction of oxidized protein for each tumor sample, the gel analyzer tool in ImageJ (https://imagej.nih.gov) was used. This tool calculates position-dependent intensities for the entirety of each band. The area under the intensity peak associated with the oxidized band was divided by the sum of the areas under the intensity peaks of both the oxidized and reduced bands.

\section{Cell cultures}

Culture medium consisted of RPMI-1640 with $15 \%$ fetal bovine serum, glutamine and penicillin/streptomycin, enriched with MEM non-essential amino acids (glycine, alanine, asparagine, aspartic acid, glutamic acid, proline, serine; each $0.1 \mathrm{mM}$, Life Technologies), fatty acid supplement (Sigma) and uridine $(50 \mu \mathrm{g} / \mathrm{L}$, Sigma). Concentrations of aspartic acid and sodium pyruvate were further supplemented individually to final concentrations of $3 \mathrm{mM}$ and $5 \mathrm{mM}$ respectively (Supplementary Table 2).

Xenograft tissue at room temperature was minced into small fragments in complete culture medium, and then gently triturated in a $1 \mathrm{~mL}$ polystyrene pipet followed by 
a 9" Pasteur pipet until approximately $80 \%$ of the tissue volume was dissociated. The resulting cell suspension was separated from the residual fragments, centrifuged at $500 \mathrm{~g}$ and resuspended in fresh medium.

In order to test the influence of ambient $\mathrm{O}_{2}$ concentration on cell growth and survival, we compared cultures routinely maintained in $\sim 20 \% \mathrm{O}_{2}$ ('normoxia', $95 \%$ air $/ 5 \% \mathrm{CO}_{2}$ ) vs $10 \%$ or $5 \% \mathrm{O}_{2}$ in Billups-Rothenberg modular incubator chambers. For the lowered $\mathrm{O}_{2}$ concentrations, the gas mixtures contained either $80 \%$ or $85 \% \mathrm{~N}_{2}$ plus $5 \% \mathrm{CO}_{2}$. Cells were plated in black 96-well assay plates (Costar) at a density of $5 \times 10^{4}$ cells/well, and survival was quantitated at 3 days using a CyQuant NF Cell Proliferation Assay kit (Molecular Probes). Use of this DNA-based assay was chosen to avoid potential confounding effects of abnormal metabolism (Quent et al. 2010). All cultures were maintained at $37^{\circ} \mathrm{C}$ in a watersaturated atmosphere.

\section{Growth factors and inhibitors}

Stem cell factor (SCF, also known as KIT ligand) was obtained from Cell Signaling Technologies. Recombinant human insulin-like growth factor 1 (IGF1) was from Abcam. ERK inhibitors U0126 and PD98059 were from New England Biolabs and Promega, respectively.

\section{Results}

\section{Histopathology}

The primary tumor was a $4.5 \mathrm{~cm}$ ulcerated gastric mass. A few patchy areas of the tumor showed classic GIST patterns (Miettinen et al. 2010) consisting of mildly discohesive, polygonal epithelioid cells with slightly eosinophilic cytoplasm and pleomorphic nuclei or hypercellular spindle cells with relatively bland nuclei. In contrast, at least $90 \%$ of cells in the tumor showed an unusual gradation from epithelioid to round shape and progressive decrease in cell size, with many cells becoming smaller than neutrophils $(\sim 12 \mu \mathrm{m})$ and exhibiting almost no cytoplasm (Fig. 1A and Supplementary Fig. 1). Some areas showed prominent myxoid material between cells or in large pools, suggesting a possible collision tumor between GIST and adenocarcinoma (Supplementary Fig. 1B). This was ruled out by immunohistochemical stains for GIST markers KIT and DOG1 (Rammohan et al. 2013) showing transition between cell types (Fig. 1B and Supplementary Fig. 4), and by the absence of staining for cytokeratin markers indicative of carcinomas. Mitoses

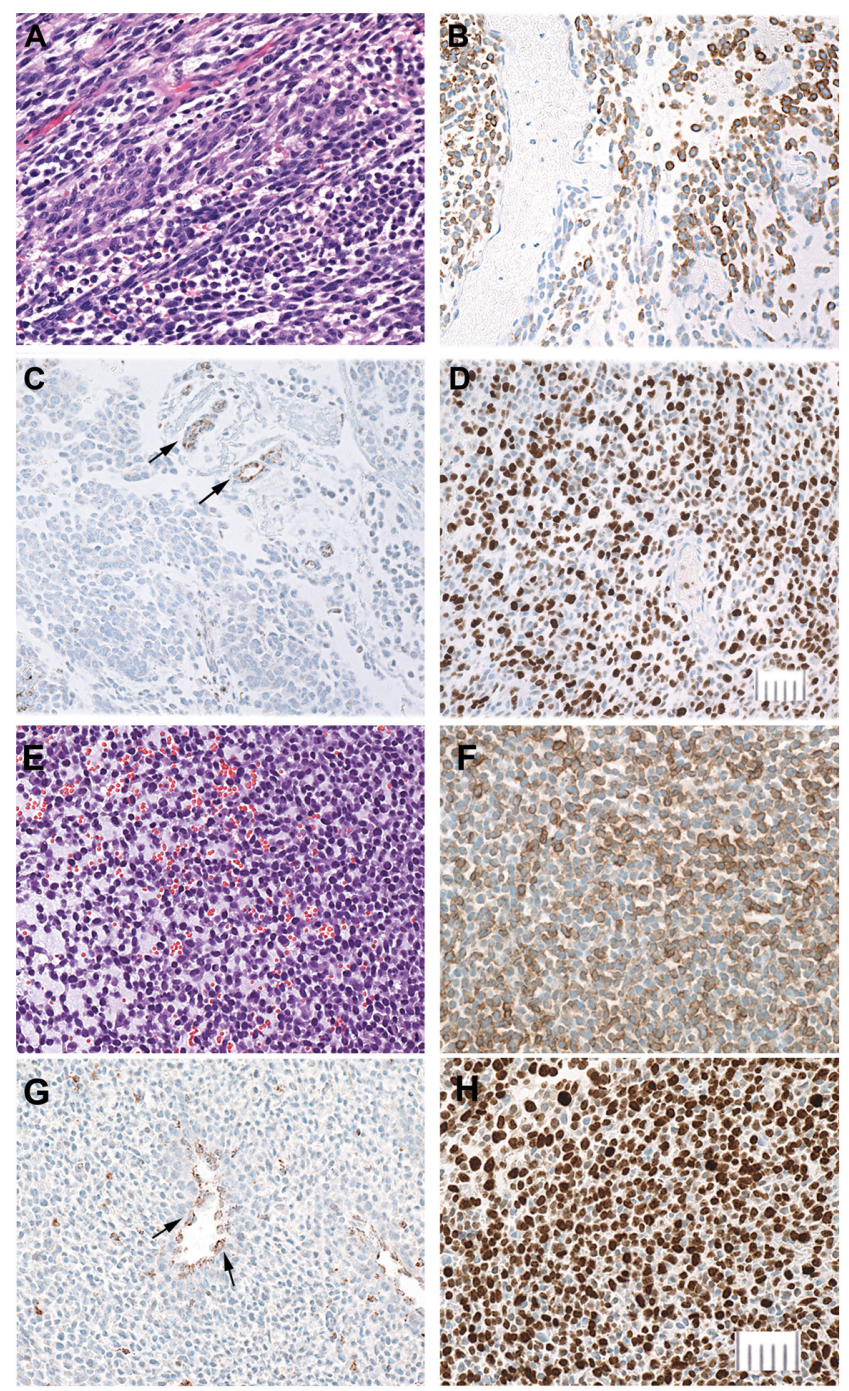

\section{Figure 1}

Major characteristics of the primary gastric tumor $(A, B, C$ and $D)$ compared to passage $3 \mathrm{PDX}(\mathrm{E}, \mathrm{F}, \mathrm{G}$ and $\mathrm{H})$. Bars $=50 \mu \mathrm{m}$. Tumor morphology (H\&E stain, A and E). Primary tumor (A) showing relatively well-differentiated spindle and epithelioid tumor cells with conspicuous eosinophilic cytoplasm (top left) transitioning to loosely cohesive, poorly differentiated tiny round cells, some smaller than $10 \mu \mathrm{m}$, with almost undetectable cytoplasm (bottom right). PDX (E) consisting entirely of small to intermediate size cells, with prominent pools of extracellular myxoid material. KIT (CD117) (B and F). Primary tumor (B) showing strong $\mathrm{KIT}$ expression in the largest cells with the most cytoplasm and reduced or absent expression in smaller cells. In the PDX (F) KIT expression shows a comparable association with the amount of cytoplasm. SDHB (C and G), In both the primary tumor (C) and PDX (G) SDHB expression is lost in all tumor cells and retained in endothelial cells (arrows), which serve as positive controls. The PDX also contains scattered SDHB-positive mouse-derived inflammatory cells between tumor cells. Ki67 ( $D$ and $H$ ). Proliferative fraction assessed by Ki67 expression is approximately twice as high in the xenograft as in the primary tumor.

were very numerous in classic epithelioid areas (up to five mitoses per single high power field) (Supplementary Fig. 2) and sparse or absent in the smallest cells. Staining for http://erc.endocrinology-journals.org https://doi.org/10.1530/ERC-18-0115 (c) 2018 Society for Endocrinology Published by Bioscientifica Ltd. Printed in Great Britain 
proliferation marker Ki67 showed a comparable pattern, ranging from approximately $80 \%$ to $20 \%$ in different parts of the tumor (Fig. 1D). An abdominal tumor deposit sampled approximately 1 year after resection of the primary consisted almost entirely small cells with patches of myxoid material (Supplementary Fig. 3).

The major morphological differences between xenografts and the patient's tumors were a more compact architecture, increasingly monomorphous population of intermediate-to-small cells, loss or greatly decreased amounts of myxoid material and uniform expression of Ki67 in 80-90\% of the tumor cells. Immunohistochemical staining for KIT was maintained through at least in vivo passage 6 , tending to be most intense in the largest cells and often undetectable in the smallest (Fig. 1). In contrast, staining for DOG1, which was sparse in the primary tumor, was almost lost by in vivo passage 4 .

The most distinctive ultrastructural features were degenerating, malformed mitochondria and extensive autophagic vacuoles containing mitochondria and other cytoplasmic components. Many cells contained numerous cytoplasmic vacuoles and loss of most identifiable cytoplasmic structures (Fig. 2).

In both the primary tumor and xenografts, immunohistochemical staining for SDHB was lost in all tumor cells and retained in endothelial cells (Fig. 1C and G) consistent with loss of the WT SDHB allele (Dahia et al. 2005, van Nederveen et al. 2009), while staining for SDHA (Korpershoek et al. 2011, Oudijk et al. 2013, Papathomas et al. 2015) was retained.
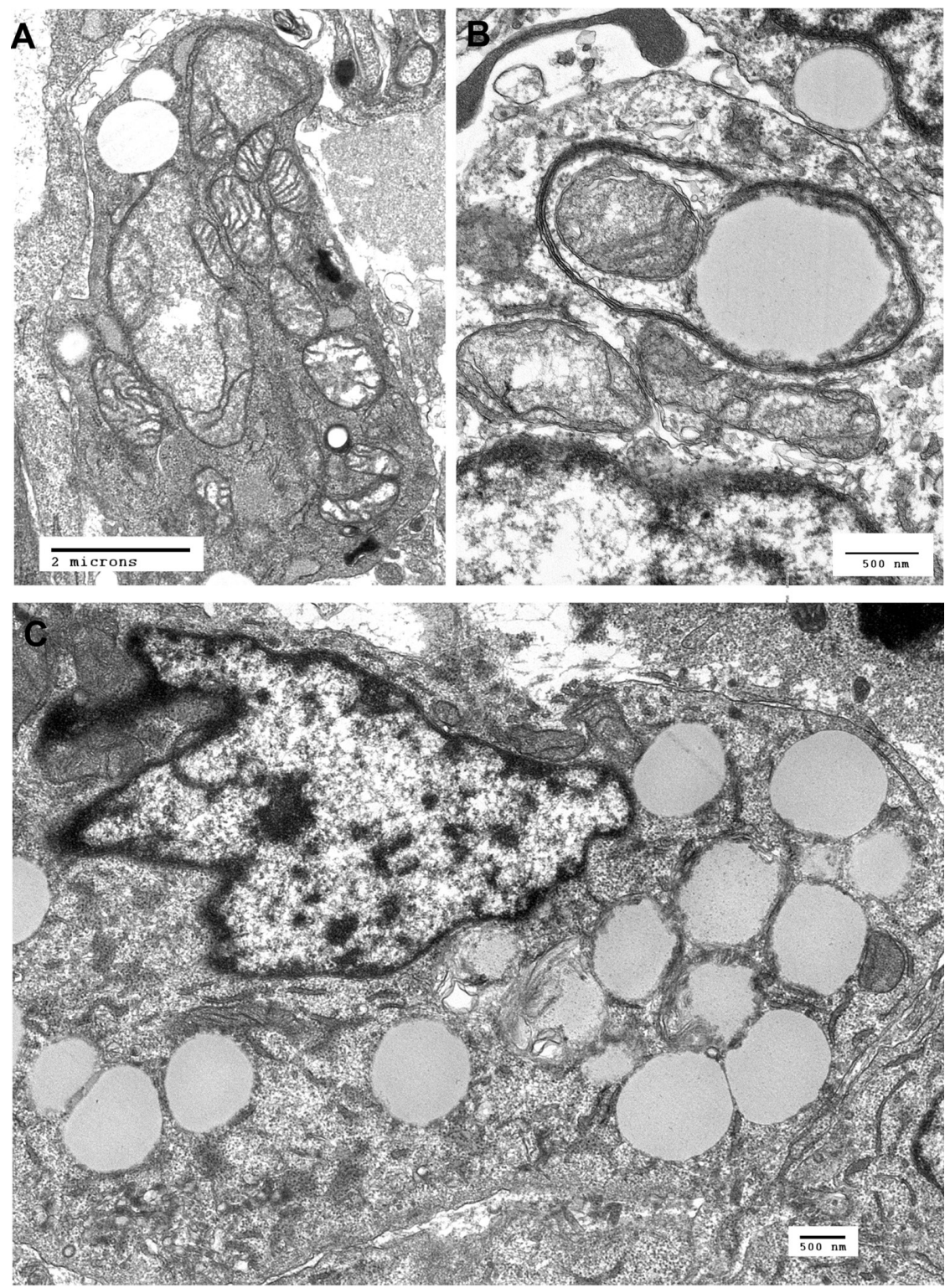

\section{Figure 2}

Ultrastructural features of the PDX cells. (A) Electron micrograph of xenograft cell showing markedly abnormal mitochondria with swelling and loss of cristae. (B) Xenograft cell with an autophagic vacuole containing a mitochondrion and amorphous material suggesting advanced degeneration of a mitochondrion or other cytoplasmic content. (C) Xenograft cell containing numerous cytoplasmic vacuoles. 


\section{Metabolite profile}

Of 55 readily identifiable metabolites in the Ian GIST xenografts, lactate comprised approximately 24\% and succinate $11 \%$ of the total (Table 1). Fumarate was almost undetectable, with a succinate/fumarate ratio of $679 \pm 151$ ( $n=4$ tumors), consistent with loss of SDH activity. Four other metabolites that each comprised $>5 \%$ of the total were taurine, glycine, myo-inositol and alanine. All others accounted for $<3 \%$. The eight most abundant metabolites comprised $>75 \%$ of the total (Table 1). In contrast, our analysis of a control xenograft of a KIT-mutated, SDHB-intact GIST model GIST-TI showed $0.54 \%$ succinate, consistent with reported values of less than $1 \%$ succinate in other non-SDH-deficient tumors (Euceda et al. 2017).

The ${ }^{13} \mathrm{C}$-glucose label ended up as a small amount of glucose, and abundant lactate, alanine and glutamate, The labeled glutamate contained nearly equal amounts of $\left[{ }^{13} \mathrm{C} 2-4,5\right] \mathrm{Glu}$ and $\left[{ }^{13} \mathrm{C} 2-2,3\right] \mathrm{Glu}$ isoptomers (Supplementary Fig. 5A), indicating nearly equal activity of pyruvate dehydrogenase $(\mathrm{PDH})$ and the anaplerotic pathway catalyzed by pyruvate carboxylase (PC) respectively (Lussey-Lepoutre et al. 2015, Bruntz et al. 2017). There was also robust incorporation of glucose into succinate. In contrast, the ratio of $\left[{ }^{13} \mathrm{C} 2-4,5\right] \mathrm{Glu}$ and $\left.{ }^{13} \mathrm{C} 2-2,3\right] \mathrm{Glu}$ isoptomers in the GIST-T1 xenograft was approximately 6:1 (Supplementary Fig. 5B). These findings are consistent with increased activity of PC previously reported in SDH-deficient cells (LusseyLepoutre et al. 2015).

Table 1 Most abundant metabolites in xenograft tissue.

\begin{tabular}{|c|c|c|}
\hline Metabolite & $\begin{array}{c}\% \text { of total } \\
\text { metabolites* } \\
(\text { mean, } n=4)\end{array}$ & Range \\
\hline Lactate & 23.85 & $21.78-26.95$ \\
\hline Taurine & 11.49 & $10.82-12.54$ \\
\hline Succinate & 11.03 & $10.76-11.40$ \\
\hline Glycine & 8.63 & $8.18-9.30$ \\
\hline Myo-inositol & 8.04 & $6.65-8.63$ \\
\hline Alanine & 5.38 & $5.04-5.72$ \\
\hline O-Phosphoethanolamine & 4.10 & $3.78-4.37$ \\
\hline Glutamate & 3.3 & $2.15-4.32$ \\
\hline Sum & 75.82 & \\
\hline
\end{tabular}

*The table lists the eight most abundant metabolites expressed as percentage of total metabolites, showing the average of percentages in four individual tumors.

\section{Molecular indicators of elevated $\mathrm{H}_{2} \mathrm{O}_{2}$ in the mitochondria and cytosol}

In light of recent studies that have linked complex II of the mitochondrial electron transport chain with increased levels of hydrogen peroxide (Quinlan et al. 2012, Kluckova et al. 2015), we hypothesized that SDH deficiency could result in increased steady-state fluxes of $\mathrm{H}_{2} \mathrm{O}_{2}$ in the mitochondria and perhaps in the cytosol. In order to measure relative $\mathrm{H}_{2} \mathrm{O}_{2}$ levels within the different GIST cells, we employed a previously described methodology (Cox et al. 2010) to measure the oxidation products of molecular targets of $\mathrm{H}_{2} \mathrm{O}_{2}$. Unlike free radical species, such as hydroxyl radical, which react readily with multiple targets inside cells, $\mathrm{H}_{2} \mathrm{O}_{2}$ reacts much more selectively within cells (Winterbourn 2008). In particular, studies have shown that virtually all of the $\mathrm{H}_{2} \mathrm{O}_{2}$ inside cells reacts with peroxiredoxins (Winterbourn 2008, Lim et al. 2015), a family of cysteine-based antioxidant proteins that form disulfide-linked dimers upon reaction with $\mathrm{H}_{2} \mathrm{O}_{2}$, on the basis of the high second-order rate coefficient for their reaction with $\mathrm{H}_{2} \mathrm{O}_{2}$ and the intracellular abundance of the these proteins (on the order of $100 \mu \mathrm{M}$ in many types of cells) (Peskin et al. 2007, Selvaggio et al. 2018). Since these enzymes act as the primary sink for intracellular $\mathrm{H}_{2} \mathrm{O}_{2}$, several studies have used the oxidation status of peroxiredoxins (i.e. oxidized dimers vs reduced monomers) as proxies for the intracellular $\mathrm{H}_{2} \mathrm{O}_{2}$ level (Low et al. 2007, Kumar et al. 2009, Sobotta et al. 2013, Poynton \& Hampton 2014). This approach combines both the $\mathrm{H}_{2} \mathrm{O}_{2}$ specificity of peroxiredoxins as well as the $\mathrm{H}_{2} \mathrm{O}_{2}$ sensitivity of cells' natural peroxide sensors.

In order to assay for oxidized peroxiredoxin dimers in both the mitochondria and cytosol in the two different types of GIST, lysates from GIST cells both with and without functional SDH were subjected to non-reducing SDS-PAGE (in which the proteins were denatured but the disulfide bonds were not reduced), transferred to a PVDF membrane, and stained for both peroxiredoxin 3 (PRDX3; located in the mitochondria) and peroxiredoxin 2 (PRDX2; located in the cytosol). The fraction of oxidized PRDX3 and PRDX2 dimers compared to reduced PRX3 and PRX2 monomers for each tumor indicated high levels of $\mathrm{H}_{2} \mathrm{O}_{2}$ in the mitochondria and cytosol of tumor cells in the xenograft tissue (Fig. 3). Densitometry showed the ratio of oxidized PRDX3 to total PRDX3 protein to be consistently higher than the corresponding ratio for PRDX2 $(0.983 \pm 0.002$ for PRDX3 compared to $0.792 \pm 0.032$ for PRDX2, $P=0.0095$ two-tailed Student's $t$-test), consistent with a greater degree of mitochondrial compromise. Comparison of the fraction 


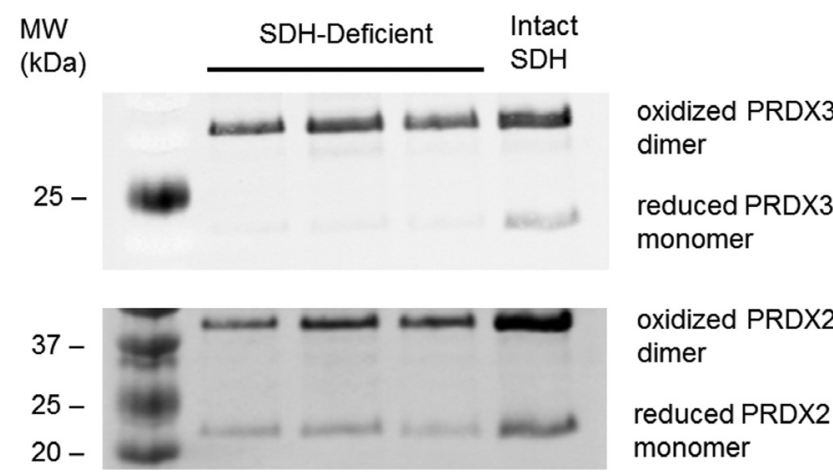

Beta-tubulin

Figure 3

Redox blot sequentially incubated with antibodies against human peroxiredoxin-2 (PRDX2) and peroxiredoxin-3 (PRDX3). The bands at approximately $22 \mathrm{kDa}$ represent the reduced monomer PRDX2 or PRDX3 proteins, while bands at about $44 \mathrm{kDa}$ represent the respective oxidized dimers. The amount of oxidized dimer relative to the total reduced monomer plus oxidized dimer in each lane is an indication of the relative amount of $\mathrm{H}_{2} \mathrm{O}_{2}$-induced stress (Cox et al. 2010). PRDX2 acts as a sensor for $\mathrm{H}_{2} \mathrm{O}_{2}$ stress in the cytosol of the cells, while PRDX3 acts in the mitochondria. Beta-tubulin is a loading control. Lanes 1-3 are from separate xenografts of SDH-deficient GIST. Lane 4, which shows the highest amounts of both oxidized dimers and reduced monomers, is from a primary conventional GIST with intact SDHB.

of oxidized PRDX3 and PRDX2 in each of the Ian GIST xenografts to a SDH-intact primary GIST specimen also suggested that SDH-deficient tumors have slightly higher $\mathrm{H}_{2} \mathrm{O}_{2}$ levels in the mitochondria and cytosol, respectively, than the conventional GIST, but additional primary tumor specimens were not available to permit adequate statistical analysis.

\section{Cell culture studies}

Cell culture experiments were undertaken with two complementary objectives. The first was to study shortterm primary cultures in order to identify critical factors regulating tumor cell survival, growth and differentiation independently of potentially confounding changes that might occur in cell lines. The second was to use data gained from those studies to guide efforts to establish cell lines, which would be needed for more extensive mechanistic investigations.

A striking and almost immediate finding was that the cells are averse to oxygen. Primary cultures were initially plated in a routinely employed atmosphere of $95 \%$ air $/ 5 \% \mathrm{CO}_{2}$. This resulted in rapid cell death, often obvious within hours and leading to loss of almost all tumor cells within two weeks. In light of the high levels of oxidative stress already present in vivo, as implied by the Prx blots, we therefore tested the effects of decreased $\mathrm{O}_{2}$ concentrations, both alone and in combination with antioxidants. Over a 3-day period in culture, there was a marked, concentration-dependent increase in tumor cell survival in the presence of $10 \%$ or $5 \% \mathrm{O}_{2}$, and survival was further enhanced by addition of either $\mathrm{N}$-acetylcysteine or a proprietary antioxidant mix. However, despite this beneficial effect, there was a sharp decline in Ki67 expression compared to the tumor cells in vivo (Fig. 4). By 2 weeks in culture almost all tumor cells had died or been overgrown by mouse cells, which grew vigorously under hypoxic conditions. The rapid switch between populations of human and mouse cells was confirmed by immunoblots that showed almost undetectable SDHB during the initial 3-day culture period, consistent with the overwhelming predominance of SDH-deficient human tumor cells, and its re-emergence by 2 weeks. In addition, immunoreactivity for Ki67 using a human-selective antibody disappeared over the same time course.

In order to get clues to understand the basis for loss of tumor cell proliferation in culture, RNA sequencing analysis was performed on the xenograft and the cultured cells to identify changes in mRNA expression. We found 226 genes upregulated by >ten-fold and 120 genes downregulated by the same amount in cells cultured in $10 \% \mathrm{O}_{2}$ as compared to the xenograft. The complete list is given in Supplementary Table 3. Analysis of pathways with Ingenuity Pathway Analysis software indicated that genes and pathways most affected in upregulated genes are matrix metalloproteases, cytokines and WNT5A and $W N T 5 B$. The cytokine induction could be an indicator of a senescence-associated secretory phenotype (Lasry \& Ben-Neriah 2015). The downregulated genes were most involved in connective tissue and growth regulation pathways. Figure 5 shows the changes in expression of genes of known interest to GIST. While there was little change in the GIST marker DOG1, there was a $>30$-fold decrease in IGF1 expression when cells were put into culture. However, addition of IGF1 to the culture of these cells was not sufficient to rescue the growth defect (data not shown). There was an almost ten-fold increase in HIF2 expression consistent with an increase in hypoxic stress in culture. There was a four-fold increase in KIT ligand expression, but a two-fold decrease in KIT receptor expression. Consistent with this, there was nearly a threefold increase in CBL expression, which can downregulate the KIT receptor through the ubiquitin pathway (Zeng et al. 2005). Thus, below we examined the expression of KIT protein in the cultures. (c) 2018 Society for Endocrinology Published by Bioscientifica Ltd. Printed in Great Britain 


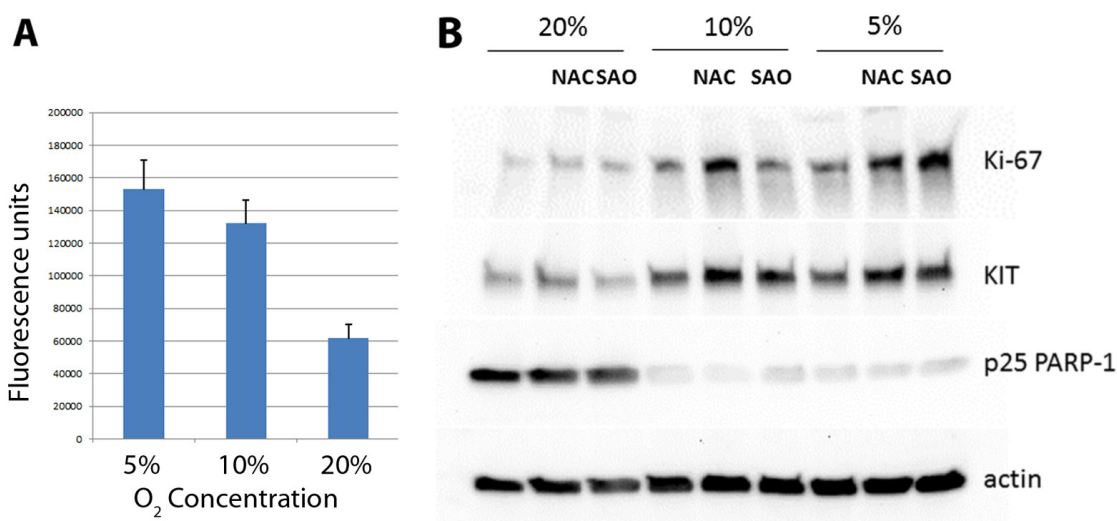

\section{Figure 4}

Effects of $\mathrm{O}_{2}$ concentration on GIST cell survival in culture. Cells were maintained at the indicated $\mathrm{O}_{2}$ concentrations for 3 days in complete medium in the presence or absence of $\mathrm{N}$-acetylcysteine (NAC, $5 \mu \mathrm{M}$ ) or a proprietary antioxidant (SAO, Sigma antioxidant; $1 \mu \mathrm{L} / \mathrm{mL}$ ). (A) Enhanced tumor cell

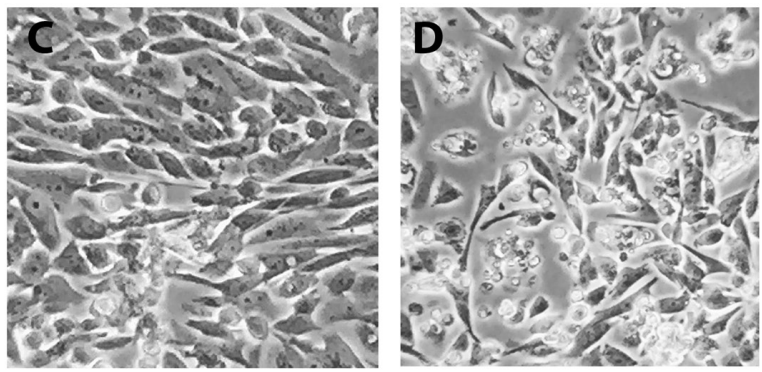
survival in reduced $\mathrm{O}_{2}$ (representative experiment), each value mean \pm S.E.M. of quadruplicate wells, $P<.03$, for 5 or $10 \%$ vs $20 \%$, difference between 5 and $10 \%$ is not significant (Mann-Whitney $U$ test). (B) Representative immunoblot showing effects of reduced $\mathrm{O}_{2}$ in cultures maintained concurrently with those in Panel A. A single immunoblot from a 4 to $15 \%$ gradient polyacrylamide gel was consecutively probed, stripped and re-probed for each of the indicated proteins. Increased survival and

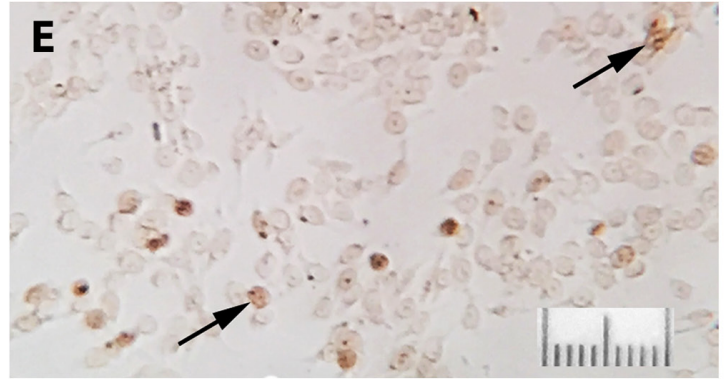
proliferative activity of GIST cells in both $10 \%$ and $5 \%$ vs $20 \% \mathrm{O}_{2}$ are reflected by greater amounts of KIT and Ki67, and by decreased amounts of cleaved poly ADP-ribose polymerase (PARP), a marker of apoptosis (Kaufmann et al. 1993). (C and D) Phase contrast photomicrographs of GIST cells in $10 \%$ and $20 \% \mathrm{O}_{2}$, respectively. (E) Immunocytochemical staining for Ki67 of GIST cells in a $10 \% \mathrm{O}_{2}$ well represented in Panel $\mathrm{A}$ (arrows indicate stained nuclei). Note only a few scattered cells labeled, compared to nearly all cells in xenograft tissue.

In addition to its $S D H B$ mutation and consequent loss of SDH activity, this GIST was unusual in also harboring a somatic KRAS mutation. This suggested that the unusual morphology, extremely high proliferative fraction, partial loss of the characteristic marker KIT and extreme fragility of the tumor cells in vitro might result from aberrant RAS/MAPK signaling. To test the effects of inhibiting this signaling cascade, we used two structurally different inhibitors of MAP kinase signaling, U0126 and PD98059 (Dokladda et al. 2005). Low concentrations of U0126, sufficient to cause approximately a 50\% decrease in MAPK phosphorylation, caused a 2- to 2.5 -fold increase in KIT expression ( $n=4$ independent experiments). This effect was not seen with PD98059. Paradoxically, this modest inhibition of ERK also maintained short-term proliferative activity, as indicated by Ki67 expression, at a higher level than in control cultures (Fig. 6). However, the percentage of labeled cells in culture remained markedly lower than that in xenograft tissue. Long-term maintenance with either inhibitor did not result in sustained proliferation or establishment of cell lines.

\section{Discussion}

The Ian GIST model is a unique human-derived model for SDH-deficient GIST, a rare mesenchymal tumor that can occur in patients with $S D H B$ mutations.

GISTs comprise $<1 \%$ of all gastrointestinal tumors (Oudijk et al. 2013). SDH-deficient GISTs, account for $\sim 3 \%$ of all GISTs and $\sim 5 \%$ of gastric GISTs in an unselected adult population (Gill et al. 2011). Approximately 50\% arise in the context of Carney Triad, a non-hereditary syndrome caused by post-zygotic promoter hypermethylation of SDHC and consisting of SDH-deficient PGL, SDH-deficient GIST and pulmonary chondroma. Approximately $30 \%$ are associated with germline mutations of SDHA (Oudijk et al. 


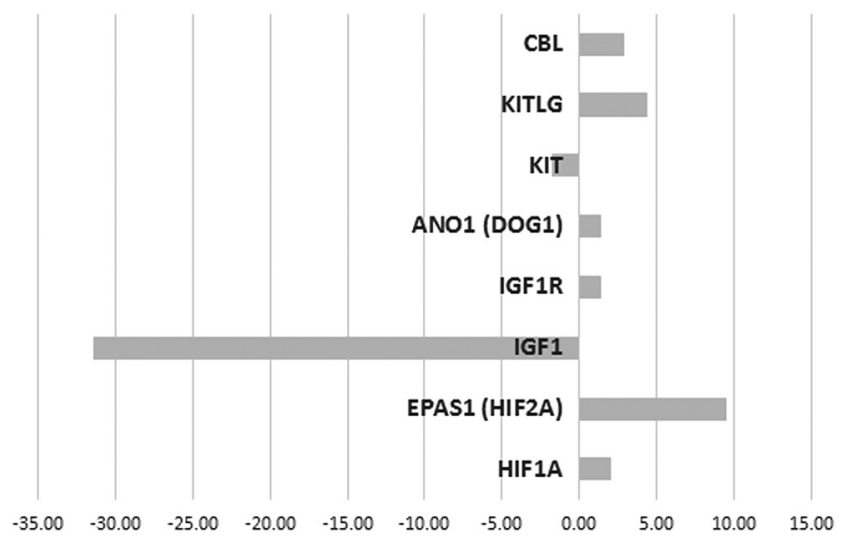

Figure 5

Fold change in expression of selected genes in cell culture compared to the xenograft. RNA sequencing analysis was preformed from the xenograft and from cells cultures in $10 \%$ oxygen for 3 days and analysis was performed as described in 'Methods' section.

2013). In a 2016 NIH study, 34 of 63 SDH-mutant GISTs harbored mutations in SDHA, 16 in SDHB, 12 in SDHC and 1 in SDHD (Boikos et al. 2016). All developed in the stomach, consistent with earlier reports.

SDH-deficient GISTs may occur in patients with or without a history of PGLs, and the lifetime risk of developing SDH-deficient GIST in patients with SDHB mutations is uncertain. It is also unclear whether $S D H B$ confers a worse prognosis than other mutated $S D H x$ genes, as is the case with paraganglioma (Gimenez-Roqueplo et al. 2008). However, most SDH-deficient GISTs follow an indolent course even after they disseminate (Boikos et al. 2016). The tumor represented by the Ian GIST model was unusual for its morphology, high proliferative fraction, decreased expression of the GIST markers KIT and DOG1 and rapid clinical course. It is likely that these characteristics resulted from the combination of germline $S D H B$ and somatic KRAS mutations.

The most distinctive morphological feature of this tumor model is the presence of tiny cells with marked autophagic activity. Comparable findings have been reported in a model of nutrient starvation caused by growth factor deprivation (Lum et al. 2005). In that model, decreased cell size was caused by autophagic consumption of cytoplasmic constituents, with progressive loss of ribosomes and the ER/Golgi network. The latter would also result in reduced expression of markers associated with differentiated function. We hypothesized that in the present model conditions comparable to exogenous nutrient starvation might be caused by superimposing metabolic demands caused by KRAS mutation (Eser et al.
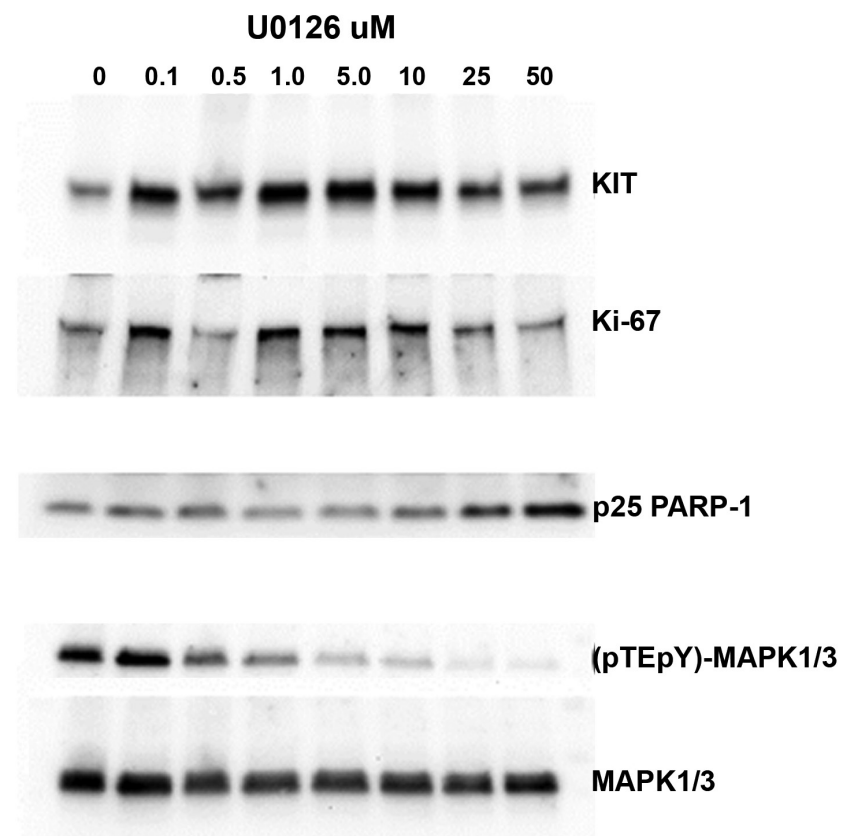

Figure 6

Representative immunoblot showing effects of MAPK inhibitor U0126 on the GIST cells in culture. Cells were maintained in $10 \% \mathrm{O}_{2}$ for 3 days in complete medium with the indicated concentrations of U0126. A single immunoblot from a 4 to $15 \%$ gradient polyacrylamide gel was consecutively probed, stripped and re-probed for each of the indicated proteins. (Bands are arranged to highlight effects on KIT and Ki67, not by molecular weight. Anomalous migration accounts for artifactually low Ki67 in lane 3.)

2014) on loss of SDH activity, which alone results in decreased function of TCA cycle anaplerotic pathways (Lussey-Lepoutre et al. 2015) and loss of ATP production by oxidative phosphorylation.

As a preliminary test of this hypothesis, we used two MEK inhibitors, U0126 and PD98059, which have previously been employed to study the effects of kinome remodeling on cellular function and differentiation (Duncan et al. 2012). Consistent with this hypothesis, concentrations of U0126 causing approximately a $50 \%$ decrease in MAPK phosphorylation in cell culture produced a 2-2.5-fold increase in KIT expression and also maintained short-term proliferative activity as indicated by Ki67 expression. PD9059 did not affect KIT but had a comparable effect on Ki67 (data not shown). While neither inhibitor is entirely specific for MEK and both might have targets outside the RAS/MAPK cascade (Dang \& Lowik 2004, Dokladda et al. 2005), these results suggest that use of the Ian GIST model to study kinome remodeling (Duncan et al. 2012) might be a fruitful area of investigation. They are of particular interest in view of 
recent studies showing that treatment of cancer patients with kinase inhibitors can select for survival of subsets of tumor cells known as drug-tolerant persister (DTP) populations (Terai et al. 2018).

Considering its unusual features, it might be asked how relevant the Ian GIST model is likely to be either to other SDH-deficient GISTs or to paragangliomas and other SDH-deficient tumors. Our most relevant findings to date concern oxygen and antioxidants. Paragangliomas are known to occur with increased frequency at high altitudes, and hypoxic signaling is a putative phenotypic modifier and driver of tumor growth in patients harboring SDHx mutations (Her et al. 2015). Based largely on murine knockdown models, hyperoxia has been proposed as a potential treatment (Her et al. 2015). In addition, $S D H x$-mutated paragangliomas are reported to show high levels of markers associated with oxidative stress (Fliedner et al. 2012), which has been proposed as both a driver and inhibitor of tumor progression in other tumor types (Pani et al. 2004). Because of the latter role, superoxide dismutase has been proposed as a therapeutic target (Pani et al. 2004). The Ian GIST model is the first from an actual human tumor of a type known to be associated with $S D H B$ mutations that can be experimentally manipulated and utilized to study mechanisms of oxygen effects and novel treatment strategies. The evidence thus far suggests that tumor growth and survival require a balance between protective effects of hypoxic signaling vs deleterious effects of oxidative stress. While reduced oxygen concentration clearly promotes tumor cell survival, a further survival benefit for tumor cells is achieved with $\mathrm{N}$-acetylcysteine or other antioxidants. This suggests use of drugs that increase rather than decrease oxidative stress as novel therapies (Raj et al. 2011, Huang et al. 2016). Another major finding is the role of autophagy in maintaining tumor cell survival in xenografts. Autophagy is largely uninvestigated in any type of SDH-deficient tumor. However, autophagy pathways are potential targets of agents that may cooperate with kinase inhibitors and other drugs as triggers of apoptotic cell death (Terai et al. 2018). It is of interest that taurine, a sulfur containing amino acid present at very high levels in our xenografts, is both an antioxidant (Schuller-Levis \& Park 2003) and a negative regulator of autophagy (Zhang et al. 2017).

The deleterious effects of oxygen observed in cell culture are not entirely unexpected because it has been recognized for some time that routine culture conditions in $95 \%$ air $/ 5 \% \mathrm{CO}_{2}$ are not physiological either for normal tissues or tumors (Carreau et al. 2011). While the $\mathrm{pO}_{2}$ in inspired air $\left(20 \% \mathrm{O}_{2}\right)$ is $150 \mathrm{mmHg}$, the value drops dramatically in normal solid tissues. For example, in liver and kidney, $\mathrm{pO}_{2}$ has been measured at $\sim 41$ and $72 \mathrm{mmHg}$ (equivalent to $\sim 5 \%$ and $10 \% \mathrm{O}_{2}$ ) respectively. In tumors of different histologic types, $\mathrm{pO}_{2}$ ranged from 0 to $54 \mathrm{mmHg}$ (Carreau et al. 2011). The most important consequence of the present study might therefore be the way the dramatic response to $\mathrm{O}_{2}$ may inform our approaches to other SDH-deficient tumors, both in terms of model development and pre-clinical drug testing. For more than 40 years, attempts to establish human paraganglioma and pheochromocytoma cell lines in cultures maintained at $95 \%$ air/5\% $\mathrm{CO}_{2}$ have been unsuccessful. Most preclinical drug testing of substitute cell lines has also been conducted under these conditions, which can exaggerate the efficacy of many chemotherapeutic agents (Carreau et al. 2011). Revisiting these studies may yield interesting results.

In summary, the Ian GIST model is potentially important both for what it might reveal specifically pertinent to this tumor type and more broadly to other types of SDH-deficient tumors, especially regarding metabolic and signaling characteristics shared across the spectrum of SDH-deficient tumor types. The presence of the KRAS mutation could make the model challenging as a tool for development of therapies.

\section{Supplementary data}

This is linked to the online version of the paper at https://doi.org/10.1530/ ERC-18-0115.

\section{Declaration of interest}

The authors declare that there is no conflict of interest that could be perceived as prejudicing the impartiality of the research reported.

\section{Funding}

This research was supported principally by grants to AST from the SDHB Pheo Para Coalition, the Pheo Para Alliance, and the Paradifference Foundation. The work utilized NMR instrumentation that was purchased with funding from a National Institutes of Health SIG grant (S10OD020073). K T S acknowledges support from the NSF GRFP.

\section{Acknowledgements}

The authors thank Dr Andrey Gritzman for providing pathology slides of the patient's primary tumor and recurrence, and Dr Andrea Califano for sharing transcriptome data not shown in this paper. 


\section{References}

Boikos SA, Pappo AS, Killian JK, LaQuaglia MP, Weldon CB, George S, Trent JC, von Mehren M, Wright JA, Schiffman JD, et al. 2016 Molecular subtypes of KIT/PDGFRA wild-type gastrointestinal stromal tumors: a report from the National Institutes of Health Gastrointestinal Stromal Tumor Clinic. JAMA Oncology 2 922-928. (https://doi.org/10.1001/jamaoncol.2016.0256)

Bolger AM, Lohse M \& Usadel B 2014 Trimmomatic: a flexible trimmer for Illumina sequence data. Bioinformatics 30 2114-2120. (https:// doi.org/10.1093/bioinformatics/btu170)

Bruntz RC, Lane AN, Higashi RM \& Fan TW 2017 Exploring cancer metabolism using stable isotope-resolved metabolomics (SIRM). Journal of Biological Chemistry 292 11601-11609. (https://doi. org/10.1074/jbc.R117.776054)

Burgess MR, Hwang E, Mroue R, Bielski CM, Wandler AM, Huang BJ, Firestone AJ, Young A, Lacap JA, Crocker L, et al. 2017 KRAS allelic imbalance enhances fitness and modulates MAP kinase dependence in cancer. Cell 168 817-829.e815. (https://doi.org/10.1016/j. cell.2017.01.020)

Carreau A, El Hafny-Rahbi B, Matejuk A, Grillon C \& Kieda C 2011 Why is the partial oxygen pressure of human tissues a crucial parameter? Small molecules and hypoxia. Journal of Cellular and Molecular Medicine 15 1239-1253. (https://doi.org/10.1111/j.1582-4934.2011.01258.x)

Cox AG, Winterbourn CC \& Hampton MB 2010 Measuring the redox state of cellular peroxiredoxins by immunoblotting. Methods in Enzymology 474 51-66. (https://doi.org/10.1016/S00766879(10)74004-0)

Dahia PL, Ross KN, Wright ME, Hayashida CY, Santagata S, Barontini M, Kung AL, Sanso G, Powers JF, Tischler AS, et al. 2005 A HIF1alpha regulatory loop links hypoxia and mitochondrial signals in pheochromocytomas. PLoS Genetics 1 e8. (https://doi.org/10.1371/ journal.pgen.0010008)

Dang ZC \& Lowik CW 2004 Differential effects of PD98059 and U0126 on osteogenesis and adipogenesis. Journal of Cellular Biochemistry 92 525-533. (https://doi.org/10.1002/jcb.20087)

Dokladda K, Green KA, Pan DA \& Hardie DG 2005 PD98059 and U0126 activate AMP-activated protein kinase by increasing the cellular AMP:ATP ratio and not via inhibition of the MAP kinase pathway. FEBS Letters 579 236-240. (https://doi.org/10.1016/j. febslet.2004.11.084)

Duncan JS, Whittle MC, Nakamura K, Abell AN, Midland AA, Zawistowski JS, Johnson NL, Granger DA, Jordan NV, Darr DB, et al. 2012 Dynamic reprogramming of the kinome in response to targeted MEK inhibition in triple-negative breast cancer. Cell 149 307-321. (https://doi.org/10.1016/j.cell.2012.02.053)

Eloqayli H, Dahl CB, Gotestam KG, Unsgard G \& Sonnewald U 2004 Changes of glial-neuronal interaction and metabolism after a subconvulsive dose of pentylenetetrazole. Neurochemistry International 45 739-745. (https://doi.org/10.1016/j.neuint.2004.02.002)

Eser S, Schnieke A, Schneider G \& Saur D 2014 Oncogenic KRAS signalling in pancreatic cancer. British Journal of Cancer 111 817-822. (https://doi.org/10.1038/bjc.2014.215)

Euceda LR, Hill DK, Stokke E, Hatem R, El Botty R, Bieche I, Marangoni E, Bathen TF \& Moestue SA 2017 Metabolic response to everolimus in patient-derived triple-negative breast cancer xenografts. Journal of Proteome Research 16 1868-1879. (https://doi. org/10.1021/acs.jproteome.6b00918)

Fliedner SM, Kaludercic N, Jiang XS, Hansikova H, Hajkova Z, Sladkova J, Limpuangthip A, Backlund PS, Wesley R, Martiniova L, et al. 2012 Warburg effect's manifestation in aggressive pheochromocytomas and paragangliomas: insights from a mouse cell model applied to human tumor tissue. PLoS One 7 e40949. (https://doi.org/10.1371/journal.pone.0040949)
Gill AJ, Chou A, Vilain R, Clarkson A, Lui M, Jin R, Tobias V, Samra J, Goldstein D, Smith C, et al. 2011 Immunohistochemistry for SDHB divides gastrointestinal stromal tumors (GISTs) into 2 distinct types. American Journal of Surgical Pathology 34 636-644. (https://doi. org/10.1097/PAS.0b013e3181d6150d)

Gimenez-Roqueplo AP, Burnichon N, Amar L, Favier J, Jeunemaitre X \& Plouin PF 2008 Recent advances in the genetics of phaeochromocytoma and functional paraganglioma. Clinical and Experimental Pharmacology and Physiology 35 376-379. (https://doi. org/10.1111/j.1440-1681.2008.04881.x)

Her YF, Nelson-Holte M \& Maher LJ 3rd 2015 Oxygen concentration controls epigenetic effects in models of familial paraganglioma. PLoS One 10 e0127471. (https://doi.org/10.1371/journal.pone.0127471)

Huang BK, Langford TF \& Sikes HD 2016 Using sensors and generators of $\mathrm{H} 2 \mathrm{O} 2$ to elucidate the toxicity mechanism of piperlongumine and phenethyl isothiocyanate. Antioxidants and Redox Signaling $\mathbf{2 4}$ 924-938. (https://doi.org/10.1089/ars.2015.6482)

Kaufmann SH, Desnoyers S, Ottaviano Y, Davidson NE \& Poirier GG 1993 Specific proteolytic cleavage of poly(ADP-ribose) polymerase: an early marker of chemotherapy-induced apoptosis. Cancer Research 53 3976-3985.

Kim D, Pertea G, Trapnell C, Pimentel H, Kelley R \& Salzberg SL 2013 TopHat2: accurate alignment of transcriptomes in the presence of insertions, deletions and gene fusions. Genome Biology 14 R36. (https://doi.org/10.1186/gb-2013-14-4-r36)

Kluckova K, Sticha M, Cerny J, Mracek T, Dong L, Drahota Z, Gottlieb E, Neuzil J \& Rohlena J 2015 Ubiquinone-binding site mutagenesis reveals the role of mitochondrial complex II in cell death initiation. Cell Death and Differentiation 6 e1749. (https://doi.org/10.1038/ cddis.2015.110)

Korpershoek E, Favier J, Gaal J, Burnichon N, van Gessel B, Oudijk L, Badoual C, Gadessaud N, Venisse A, Bayley JP, et al. 2011 SDHA immunohistochemistry detects germline SDHA gene mutations in apparently sporadic paragangliomas and pheochromocytomas. Journal of Clinical Endocrinology and Metabolism 96 E1472-E1476. (https://doi.org/10.1210/jc.2011-1043)

Kumar V, Kitaeff N, Hampton MB, Cannell MB \& Winterbourn CC 2009 Reversible oxidation of mitochondrial peroxiredoxin 3 in mouse heart subjected to ischemia and reperfusion. FEBS Letters $\mathbf{5 8 3}$ 997-1000. (https://doi.org/10.1016/j.febslet.2009.02.018)

Lasry A \& Ben-Neriah Y 2015 Senescence-associated inflammatory responses: aging and cancer perspectives. Trends in Immunology 36 217-228. (https://doi.org/10.1016/j.it.2015.02.009)

Letouze E, Martinelli C, Loriot C, Burnichon N, Abermil N, Ottolenghi C, Janin M, Menara M, Nguyen AT, Benit P, et al. 2013 SDH mutations establish a hypermethylator phenotype in paraganglioma. Cancer Cell 23 739-752. (https://doi.org/10.1016/j. ccr.2013.04.018)

Liao Y, Smyth GK \& Shi W 2014 featureCounts: an efficient general purpose program for assigning sequence reads to genomic features. Bioinformatics 30 923-930. (https://doi.org/10.1093/bioinformatics/ btt656)

Lim JB, Huang BK, Deen WM \& Sikes HD 2015 Analysis of the lifetime and spatial localization of hydrogen peroxide generated in the cytosol using a reduced kinetic model. Free Radical Biology and Medicine 89 47-53. (https://doi.org/10.1016/j. freeradbiomed.2015.07.009)

Low FM, Hampton MB, Peskin AV \& Winterbourn CC 2007 Peroxiredoxin 2 functions as a noncatalytic scavenger of low-level hydrogen peroxide in the erythrocyte. Blood 109 2611-2617. (https://doi.org/10.1182/blood-2006-09-048728)

Lum JJ, Bauer DE, Kong M, Harris MH, Li C, Lindsten T \& Thompson CB 2005 Growth factor regulation of autophagy and cell survival in the absence of apoptosis. Cell 120 237-248. (https://doi. org/10.1016/j.cell.2004.11.046)
(2) 2018 Society for Endocrinology Published by Bioscientifica Ltd. Printed in Great Britain 
Lussey-Lepoutre C, Hollinshead KE, Ludwig C, Menara M, Morin A, Castro-Vega LJ, Parker SJ, Janin M, Martinelli C, Ottolenghi C, et al. 2015 Loss of succinate dehydrogenase activity results in dependency on pyruvate carboxylation for cellular anabolism. Nature Communications 6 8784. (https://doi.org/10.1038/ncomms9784)

Miettinen M, Fletcher CDM, Kindblom L-G \& Tsui WMS 2010 Mesenchymal tumours of the tomach. In WHO Classification of Tumours of the Digestive System, 4th ed, pp 74-76. Eds FT Bosman, F Carneiro, RH Hruban \& ND Theise. Lyon, France: IARC Press.

Mullassery D \& Weldon CB 2016 Pediatric/'wildtype' gastrointestinal stromal tumors. Seminars in Pediatric Surgery 25 305-310. (https://doi. org/10.1053/j.sempedsurg.2016.09.004)

Oudijk L, Gaal J, Korpershoek E, van Nederveen FH, Kelly L, Schiavon G, Verweij J, Mathijssen RH, den Bakker MA, Oldenburg RA, et al. 2013 SDHA mutations in adult and pediatric wild-type gastrointestinal stromal tumors. Modern Pathology 26 456-463. (https://doi.org/10.1038/modpathol.2012.186)

Pani G, Colavitti R, Bedogni B, Fusco S, Ferraro D, Borrello S \& Galeotti T 2004 Mitochondrial superoxide dismutase: a promising target for new anticancer therapies. Current Medicinal Chemistry 11 1299-1308. (https://doi.org/10.2174/0929867043365297)

Papathomas TG, Oudijk L, Persu A, Gill AJ, van Nederveen F, Tischler AS, Tissier F, Volante M, Matias-Guiu X, Smid M, et al. 2015 SDHB/SDHA immunohistochemistry in pheochromocytomas and paragangliomas: a multicenter interobserver variation analysis using virtual microscopy: a Multinational Study of the European Network for the Study of Adrenal Tumors (ENS@T). Modern Pathology 28 807-821. (https://doi.org/10.1038/modpathol.2015.41)

Peskin AV, Low FM, Paton LN, Maghzal GJ, Hampton MB \& Winterbourn CC 2007 The high reactivity of peroxiredoxin 2 with $\mathrm{H}(2) \mathrm{O}(2)$ is not reflected in its reaction with other oxidants and thiol reagents. Journal of Biological Chemistry 282 11885-11892. (https://doi.org/10.1074/jbc.M700339200)

Powers JF, Evinger MJ, Tsokas P, Bedri S, Alroy J, Shahsavari M \& Tischler AS 2000 Pheochromocytoma cell lines from heterozygous neurofibromatosis knockout mice. Cell and Tissue Research $\mathbf{3 0 2}$ 309-320. (https://doi.org/10.1007/s004410000290)

Poynton RA \& Hampton MB 2014 Peroxiredoxins as biomarkers of oxidative stress. Biochimica et Biophysica Acta 1840 906-912. (https:// doi.org/10.1016/j.bbagen.2013.08.001)

Quent VM, Loessner D, Friis T, Reichert JC \& Hutmacher DW 2010 Discrepancies between metabolic activity and DNA content as tool to assess cell proliferation in cancer research. Journal of Cellular and Molecular Medicine 14 1003-1013. (https://doi. org/10.1111/j.1582-4934.2010.01013.x)

Quinlan CL, Orr AL, Perevoshchikova IV, Treberg JR, Ackrell BA \& Brand MD 2012 Mitochondrial complex II can generate reactive oxygen species at high rates in both the forward and reverse reactions. Journal of Biological Chemistry 287 27255-27264. (https:// doi.org/10.1074/jbc.M112.374629)

Raj L, Ide T, Gurkar AU, Foley M, Schenone M, Li X, Tolliday NJ, Golub TR, Carr SA, Shamji AF, et al. 2011 Selective killing of cancer cells by a small molecule targeting the stress response to ROS. Nature 475 231-234. (https://doi.org/10.1038/nature10167)

Rammohan A, Sathyanesan J, Rajendran K, Pitchaimuthu A, Perumal SK, Srinivasan U, Ramasamy R, Palaniappan R \& Govindan M 2013 A gist of gastrointestinal stromal tumors: a review. World Journal of
Gastrointestinal Oncology 5 102-112. (https://doi.org/10.4251/wjgo. v5.i6.102)

Ricci R 2016 Syndromic gastrointestinal stromal tumors. Hereditary Cancer in Clinical Practice 14 15. (https://doi.org/10.1186/s13053-0160055-4)

Robinson MD, McCarthy DJ \& Smyth GK 2010 edgeR: a bioconductor package for differential expression analysis of digital gene expression data. Bioinformatics 26 139-140. (https://doi.org/10.1093/ bioinformatics/btp616)

Schuller-Levis GB \& Park E 2003 Taurine: new implications for an old amino acid. FEMS Microbiology Letters 226 195-202. (https://doi. org/10.1016/S0378-1097(03)00611-6)

Selvaggio G, Coelho P \& Salvador A 2018 Mapping the phenotypic repertoire of the cytoplasmic 2-Cys peroxiredoxin - thioredoxin system. 1. Understanding commonalities and differences among cell types. Redox Biology 15 297-315. (https://doi.org/10.1016/j. redox.2017.12.008)

Sobotta MC, Barata AG, Schmidt U, Mueller S, Millonig G \& Dick TP 2013 Exposing cells to $\mathrm{H} 2 \mathrm{O} 2$ : a quantitative comparison between continuous low-dose and one-time high-dose treatments. Free Radical Biology and Medicine 60 325-335. (https://doi.org/10.1016/j. freeradbiomed.2013.02.017)

Taguchi T, Sonobe H, Toyonaga S, Yamasaki I, Shuin T, Takano A, Araki K, Akimaru K \& Yuri K 2002 Conventional and molecular cytogenetic characterization of a new human cell line, GIST-T1, established from gastrointestinal stromal tumor. Laboratory Investigation 82 663-665. (https://doi.org/10.1038/labinvest.3780461)

Terai H, Kitajima S, Potter DS, Matsui Y, Quiceno LG, Chen T, Kim TJ, Rusan M, Thai TC, Piccioni F, et al. 2018 ER stress signaling promotes the survival of cancer 'persister cells' tolerant to EGFR tyrosine kinase inhibitors. Cancer Research 78 1044-1057. (https:// doi.org/10.1158/0008-5472.CAN-17-1904)

van Nederveen FH, Gaal J, Favier J, Korpershoek E, Oldenburg RA, de Bruyn EM, Sleddens HF, Derkx P, Riviere J, Dannenberg H, et al. 2009 An immunohistochemical procedure to detect patients with paraganglioma and phaeochromocytoma with germline SDHB, SDHC, or SDHD gene mutations: a retrospective and prospective analysis. Lancet Oncology 10 764-771. (https://doi.org/10.1016/ S1470-2045(09)70164-0)

Winterbourn CC 2008 Reconciling the chemistry and biology of reactive oxygen species. Nature Chemical Biology 4 278-286. (https://doi. org/10.1038/nchembio.85)

Wishart DS, Knox C, Guo AC, Eisner R, Young N, Gautam B, Hau DD, Psychogios N, Dong E, Bouatra S, et al. 2009 HMDB: a knowledgebase for the human metabolome. Nucleic Acids Research $\mathbf{3 7}$ D603-D610. (https://doi.org/10.1093/nar/gkn810)

Wu H, Southam AD, Hines A \& Viant MR 2008 High-throughput tissue extraction protocol for NMR- and MS-based metabolomics. Analytical Biochemistry 372 204-212. (https://doi.org/10.1016/j.ab.2007.10.002)

Zeng S, Xu Z, Lipkowitz S \& Longley JB 2005 Regulation of stem cell factor receptor signaling by $\mathrm{Cbl}$ family proteins (Cbl-b/c-Cbl). Blood 105 226-232. (https://doi.org/10.1182/blood-2004-05-1768)

Zhang Y, Ren S, Liu Y, Gao K, Liu Z \& Zhang Z 2017 Inhibition of starvation-triggered endoplasmic reticulum stress, autophagy, and apoptosis in ARPE-19 cells by taurine through modulating the expression of calpain-1 and calpain-2. International Journal of Molecular Sciences 18 2146. (https://doi.org/10.3390/ijms18102146)

Received in final form 25 June 2018

Accepted 28 June 2018

Accepted Preprint published online 2 July 2018
(2) 2018 Society for Endocrinology Published by Bioscientifica Ltd. Printed in Great Britain 